\title{
Determinants of body weight regulation in humans
}

\author{
Milene Moehlecke', Luis Henrique Canani', Lucas Oliveira \\ Junqueira e Silva ${ }^{2}$, Manoel Roberto Maciel Trindade ${ }^{3}$, \\ Rogerio Friedman', Cristiane Bauermann Leitão'
}

${ }^{1}$ Divisão de Endocrinologia, Serviço de Endocrinologia, Hospital de Clínicas de Porto Alegre (HCPA), Porto Alegre, RS, Brasil

2 Faculdade de Medicina, Universidade Federal do Rio Grande do Sul (UFRGS), Porto Alegre, RS, Brasil ${ }^{3}$ Departamento de Cirurgia, Serviço de Cirurgia do Aparelho Digestivo, HCPA), Porto Alegre, RS, Brasil

\section{Correspondence to:}

Milene Moehlecke

Serviço de Endocrinologia,

Hospital de Clínicas de Porto Alegre

Rua Ramiro Barcelos, 2350,

prédio $12,4^{\circ}$ andar

90035-003 - Porto Alegre, RS, Brasil

milenemoehlecke@yahoo.com.br

Received on May/18/2015

Accepted on Oct/7/2015

DOI: $10.1590 / 2359-3997000000129$

\begin{abstract}
Body weight is regulated by the ability of hypothalamic neurons to orchestrate behavioral, endocrine and autonomic responses via afferent and efferent pathways to the brainstem and the periphery. Weight maintenance requires a balance between energy intake and energy expenditure. Although several components that participate in energy homeostasis have been identified, there is a need to know in more detail their actions as well as their interactions with environmental and psychosocial factors in the development of human obesity. In this review, we examine the role of systemic mediators such as leptin, ghrelin and insulin, which act in the central nervous system by activating or inhibiting neuropeptide Y, Agouti-related peptide protein, melanocortin, transcript related to cocaine and amphetamine, and others. As a result, modifications in energy homeostasis occur through regulation of appetite and energy expenditure. We also examine compensatory changes in the circulating levels of several peripheral hormones after diet-induced weight loss. Arch Endocrinol Metab. 2016;60(2):152-62
\end{abstract}

\section{Keywords}

Appetite regulation; energy metabolism; energy expenditure; body weight

\section{INTRODUCTION}

$\mathrm{O}$ besity is a chronic multifactorial disease of complex etiology, resulting from the chronic disruption between energy intake and energy expenditure, involving genetic, environmental, lifestyle, and emotional factors. The body mass index (BMI) calculated by dividing weight (in kilograms) by height (in meters) squared, is one of the available tools for assessment of overall adiposity. The prevalence of overweight, defined as BMI between 25 and $29.9 \mathrm{~kg} / \mathrm{m}^{2}$ and obesity, as BMI greater than or equal to $30 \mathrm{~kg} / \mathrm{m}^{2}$ has increased progressively in recent decades. Data from the National Health and Nutrition Examination Survey (NHANES) show that approximately $70 \%$ of North American adults are overweight and $35 \%$ are obese. Obese individuals have an increased risk of obesity-related chronic complications and mortality from all causes proportional to the increasing of BMI (1). The addition of waist circumference (WC) to BMI seems to predict a greater variance in health risk than does BMI alone (2). Increased central adiposity is associated with an increased risk of morbidity and mortality (3). In adults with a BMI of 25 to $34.9 \mathrm{~kg} / \mathrm{m}^{2}$, a WC greater than $102 \mathrm{~cm}$ (40 in) for men and $88 \mathrm{~cm}$ ( $35 \mathrm{in}$ ) for women is associated with a greater risk of chronic complications (2).

In this review, we synthesize the main neurohumoral mechanisms involved in the regulation of energy metabolism and the evidence for their possible association with the development of obesity. In addition, we discuss briefly about compensatory changes in the circulating levels of several peripheral hormones after weight loss for understanding the physiological basis of weight regain after diet-induced weight loss.

\section{INTEGRATION OF AFFERENT AND EFFERENT SYSTEM AND COMPLEX REGULATOR}

The appetite control derives from a variety of afferent stimuli (afferent pathways) to be processed in the 
central nervous system (CNS) (processing unit) and finally signals the intake and regulates energy store (4). Sense organs, humoral signals, nutrients and vagals afferents are involved in feeding in the short term (5). Processing unit of the CNS includes hypothalamus and brain stem. Efferent system, a complex regulator of appetite and satiety, includes limbic cortex, thalamus, brain stem, insula, hippocampus and base nuclei that taken together with autonomic thermogenic effectors will regulate the energy expenditure (Figure 1). The interaction between these components finally will result in increased or decreased in energy stores.

\section{AFFERENT SYSTEM: HORMONES SIGNALING ENERGY RESERVES}

\section{Role of the adipose tissue}

Adipose tissue is the major reservoir of energy in the body. In mammals, two types of adipose tissue occur: white and brown both directly regulated by the auto- nomic nervous system (6). Sympathetic innervation is mainly related to the catabolic actions, such as lipolysis, mediated by $\beta$-adrenergic receptor-dependent activity of the enzyme hormone-sensitive lipase (6). On the other hand, the parasympathetic activation is involved in anabolic effects, such as uptake of glucose and fatty acids stimulated by insulin (6).

Recent evidence has shown that the adipose tissue also plays an important role in the integration of endocrine, metabolic and inflammatory signals to control energy homeostasis, through the production of a variety of bioactive proteins, together referred to as "adipokines", which include: leptin, adiponectin, resistin, visfatin, tumor necrosis factor - alpha (TNF-alpha), plasminogen inhibitor type 1 , among others. Some of these are associated with disruption in metabolism and obesity and will be described below.

\section{Leptin}

Leptin is produced mainly in white adipose tissue and its concentration, in normal individuals, is proportional to the amount of adipose tissue, being

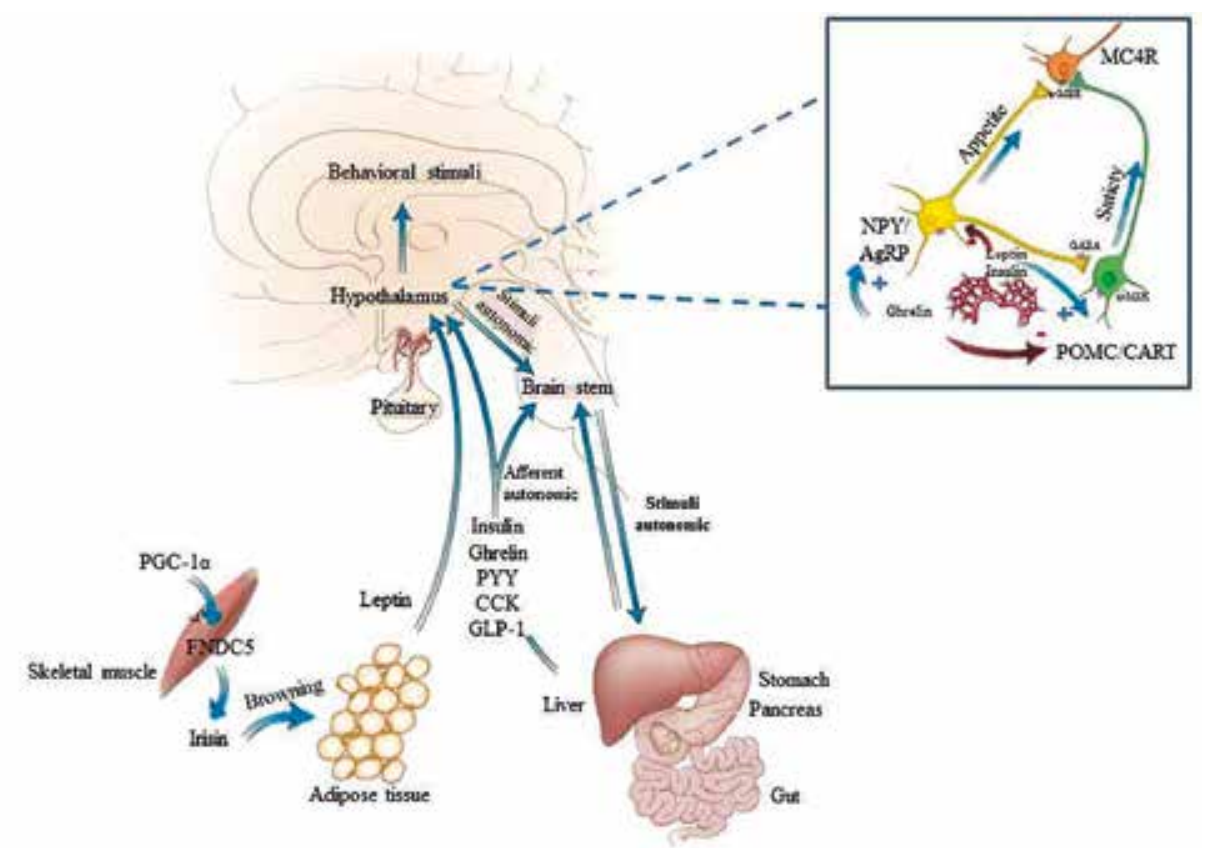

Figure 1. Regulation of energy homeostasis between central nervous system and peripheral signals (adapted 5,47). The determination of body weight results from a complex interaction of peripheral signals from the gastrointestinal tract, adipose tissue with the CNS. The hypothalamic control of energy homeostasis comes from the ability of hypothalamic neurons to orchestrate behavioral, endocrine and autonomic responses, via afferent and efferent pathways to the brain stem and the periphery. In the muscle, peroxisome proliferator activated receptor $\gamma$ coactivator $1 \alpha$ (PGC-1 $\alpha$ ) stimulates the expression of the membrane protein fibronectin type III domain containing 5 (FNDC5), which is proteolytically cleaved to form irisin, a myokine that drives the transformation of white fat cells into brite cells, an effect known as "browning" of subcutaneous adipose tissue. AgRP: Agouti-related peptide; CART: co-caine and amphetamine regulated transcript; CCK: cholecystokinin; GLP-1: glucagon like-peptide 1; MC4R: melanocortin 4 receptor; NPY: neuropeptide y; POMC: pro-opiomelanocortin; PYY: peptide YY. 
higher in subcutaneous adipose tissue compared to visceral tissue (7). Leptin, which is stimulated by insulin, acts by inhibiting the release of neuropeptide Y (NPY)/Agouti-related peptide (AgRP), and through increased activation of neurons of the arcuate nucleus (ARC) of the hypothalamus that express the pro-opiomelanocortin (POMC) (8). Thus, the NPY/AgRP neurons are thought to constitute a potent feeding system that is actively opposed by the POMC/cocaine and amphetamine regulated transcript (CART) satiety system (9). Leptin also stimulates other anorexigenic peptides such as corticotropin releasing hormone $(\mathrm{CRH})$ and $\mathrm{CART}$, resulting in catabolic effects of prolonged action and decreased food intake with increased energy expenditure (9). In polygenic obesity, increased leptin levels suggest resistance to its anorexigenic effects. It is likely that a failure in its production and/or action on its hypothalamic receptor could lead to a positive energy balance, generating hyperphagia and severe obesity (10). In human or animal obesity models with lack the leptin receptor or ligand, high leptin levels do not inhibit the feeding; its absence is a strong stimulus to induce feeding though (9). This can be considered an evolutionarily advantageous system as it allows for excess energy storage when resources are transiently available but drives feeding behavior under more limiting conditions (11). However, leptin signaling becomes maladaptive under obesogenic environment with easy access to highly palatable and energy dense foods.

\section{Visfatin}

Visfatin is an adipokine highly expressed in visceral fat that has been associated to numerous proinflammatory effects and glucose homeostasis (12). Obesity and type 2 diabetes mellitus (T2DM) were associated with elevated circulating plasma visfatin in meta-analysis of observational studies (13). It has been suggested that visfatin is significantly increased during the process of adipogenesis, being involved in adipocyte differentiation and proliferation (14). Its elevated plasma levels in association with insulin resistance and T2DM are probably a consequence of the hyperglycemic milieu (13). Its exact biological action remains uncertain being necessary further investigation to clarify the connection between visfatin, and pathologic conditions as obesity and T2DM (13).

\section{Adiponectin}

Adiponectin appears to play an important role in the modulation of glucose and lipid metabolism in insulin sensitive tissues, both in animals and humans models (15). Its production is stimulated by peroxisome proliferator-activated receptor gamma (PPAR-gamma) and inhibited by catecholamines, and TNF-alpha (16). It acts systemically through two receptors, adipo-Rl and adipo-R2 (expressed in muscle tissue and in hepatocytes, respectively), increasing sensitivity to insulin, reducing hepatic glucose production and stimulating fatty acid oxidation (16). In humans, plasma adiponectin levels are significantly lower in states of insulin resistance, including type $2 \mathrm{DM}$ (17). Two loci related to metabolic syndrome components were identified in the same chromosome $(3 \mathrm{q} 27)$ where the adiponectin gene is located, reinforcing the role of this hormone in obesity (18). The fact that obesity is characterized by a state of adiponectin deficiency makes this an interesting target for possible therapeutic interventions.

\section{Resistin}

The main biological effects of resistin are associated with increases in blood glucose levels and obesity in some animal models, partially explained as a consequence of increased hepatic glucose production (19). In humans, resistin reduces insulin-stimulated glucose uptake in isolated adipocytes. The mechanisms underlying these effects remain unclear, although data aim to the suppression of AMP-activated protein kinase (AMPK) activity by resistin, primarily in the liver, due to activation of cytokine stimulation-3 suppressor. The phenotypes of humanized resistin transgenic mice suggest similar roles of murine and human resistin in insulin resistance (20). Elevated resistin levels are associated with greater risk for type $2 \mathrm{DM}$, increased inflammatory markers and atherosclerosis (21).

\section{Role of the intestine}

In the gut, chemo and mechano-receptors give information about the amount of nutrients that is temporarily stored in the gastrointestinal tract (8). In the stomach, nutrients are perceived by vagal stretch and sensors present in the gastric mucosa (8). Moreover, intestinal peptides, stimulated by food intake, mediate satiety centers in the brain stem. Signals received by the brain stem centers to regulate long term weight use neural connections with 
the hypothalamus to regulate total daily intake, by adjusting the size of the meals, their number or both (22).

\section{Ghrelin}

Ghrelin is a potent orexigenic hormone that stimulates food intake (10). The stomach is the primary site of ghrelin, although lower concentrations may be found in other organs as small intestine and hypothalamus (10). It is likely that this peptide is responsible for the start of a meal. Its levels are elevated one to two hours before the meal, and are decreased soon after (23). Its orexigenic action results from activation of NPY/AgRP neurons in the ARC (10). The pharmacological blockade of ghrelin receptors in these neurons attenuates food intake in rodents (24). The exogenous administration of ghrelin is associated with increased food intake, reduced resting energy expenditure and catabolism in the adipose tissue (25).

\section{Glucagon like-peptide 1 (GLP-1)}

GLP-1, derived from the proglucagon gene, is the prototypical incretin hormone. GLP-1 release is triggered by ingestion of carbohydrates, fats, and protein and seems to reflect, at least in part, the direct sensing of luminal nutrients by the apical processes of the intestinal L-cells and the hindbrain, primarily in the nucleus of the solitary tract (26). GLP-1 acts as satiety signals through the GLP-1 receptor (GLP-1R). GLP-1R can also be stimulated exogenously via long lasting GLP-1 analogs (27). In humans, peripheral GLP-1 administration to normal and diabetic subjects induces satiety and reduces food intake in short term studies (28). Chronic continuous GLP-1 administration to human diabetic subjects was associated with modest weight loss (28). The effects of GLP-1 on appetite may be mediated in part via inhibition of gastric emptying and also reflect direct effects of GLP-1 on satiety and induction of taste aversion (29). GLP-1R stimulation reduces food reward behavior (28). Peripherally, GLP-1 stimulates lipolysis, adiponectin expression and increases thermogenesis with increased energy expenditure (30).

\section{Peptide YY (PYY)}

PYY is released in the gastrointestinal tract in the postprandial period. It is important in prompting the end of the meal (8). It acts by inhibiting the activity of neurons NPY/AgRP and stimulating POMC/CART in the ARC of the hypothalamus. Infusion of PYY at phy- siological doses results in inhibition of gastric emptying and gastric acid and pancreatic exocrine secretion (31). These effects are mediated by direct action of PYY on the dorsal vagal complex (31). The peripheral administration of pharmacological doses of this peptide seems to have a short anorectic effect in humans, suggesting that PYY functions as a satiety factor (32). The mechanisms underlying the action of PYY in reducing food intake have not been fully elucidated. Its contribution in long term regulation of energy deposits, however, needs to be better evaluated.

\section{Cholecystokinin (CCK)}

CCK is released approximately 15 min after meal initiation by the presence of lipids and proteins, inducing anorectic effect by vagal afferent pathways (33). There are several known bioactive forms of CCK, such as CCK-8 and CCK-58 and two types of CCK receptors, CCKA and CCKB (33). CCKA (also known as CCKI) seems to play a more important role in food intake regulation. CCK regulates short term feeding behavior in mice through selectively satiation, namely, the termination of eating at meal end (34). Deficits in satiation signaling during obesogenic feeding have been proposed to play a role in hyperphagia and weight gain in animals prone to become obese. The effects of CCK on suppression of food intake of high fat fed obese prone and resistant rats and its role on lipid-induced satiation was recently examined (35). Obese prone rats have reduced feeding responses to exogenous CCK and have deficits in endogenous CCK signaling compared to resistant rats (35). These results suggest that high fat feeding leads to impairments in lipid-induced CCK satiation signaling in obese-prone rats, potentially contributing to hyperphagia and weight gain. Moreover, to evaluate CCK function on meal size and intermeal interval, CCK was injected in experimental rodents during every spontaneous meal by intraperitoneal catheters with extended of both (36). However, the absence of CCK signaling seems has no effect on long term energy homeostasis. The influence of exogenous CCK-8 on satiety effect was first reported in obese humans in 1982 and revealed that subjects stopped eating sooner during CCK-8 administration, even though maintaining the same eat rate (37). Studies have been shown that in lean individuals, the increase in postprandial CCK levels is high and fast, which may result in earlier occurrence of satiation, while in obese individuals, postprandial CCK levels remain increased for longer (38). 


\section{Insulin}

Insulin is a circulating afferent signal, whose concentrations increasing with BMI, with many central effects similar to leptin (10). Mice without insulin receptors in the CNS develop hyperphagia and fat deposition, while insulin agonists exert the opposite effect (39). In view of insulin and leptin regulate body weight via negative feedback, the exogenous administration of these hormones would presumably promote weight loss (10). However, obese individuals become resistant to insulin and leptin, and remain hyperphagic despite high circulating levels of both hormones (40). Researchers have attempted to elucidate the mechanisms associated with resistance to the action of these hormones, as well as to develop more effective agonists of leptin and insulin analogues with selective action in the CNS, without peripheral anabolic effects (10).

\section{Central circuits: regulation of energy homeostasis}

The regulation of energy homeostasis occurs through interconnection between a wide variety of signals from the gastrointestinal tract, via either sensory afferents or via circulation, at the dorsal vagal complex to multiple brain circuits to affect autonomic neuronal pathways and endocrine organs (41). This interaction will result in appetite control, in satiety, defined as sensation of satisfaction or fullness, and in the pleasure associated with food, related to palatability and reward derived from food (9).

The hypothalamus and the brain stem act as the two main centers, which receive and integrate peripheral signals that then cross-regulate each other and communicate with higher brain regions such as the anterior forebrain mesolimbic reward system (22). Peptides can regulate both appetite and energy expenditure as neurotransmitters can act in an even more complex way, through multiple receptors. Its effects may vary according to the anatomical region involved (42). A summary of the principal peptides and neurotransmitters involved in the regulation of body weight are presented in Table 1.

\section{Hypothalamus}

Within the hypothalamus, several hypothalamic sites are thought to be key in regulating energy homeostasis. The ARC of the hypothalamus contains two populations of neurons that continuously monitor signals reflecting energy status and promote the appropriate behavioral and metabolic responses to changes in energy demand. Neurons making POMC decrease food intake and increase energy expenditure through activation of $\mathrm{G}$ protein-coupled melanocortin receptors (MCR) via release of alpha-melanocyte-stimulating hormone ( $\alpha$-MSH) (Figure 1) (43). AgRP acts antagonizing the action of $\alpha-\mathrm{MSH}$ at the melanocortin 4 receptor (MC4R). Overexpression of AgRP can lead to obesity (44). MC4R is widely found in the hypothalamus and activation of this receptor by $\alpha-\mathrm{MSH}$ reduces food intake (45). Deletions or mutations in the MC4R are associated with obesity. It is estimated that $5 \%$ of cases of early-onset and severe obesity are the result of heterozygous mutations of MC4R (46).

Neurons expressing orexigenic neuropeptides as NPY, AgRP, MCH neurons act increasing feeding and decreasing energy expenditure primarily by opposing the anorexigenic/catabolic actions of the POMC through both via competitive inhibition of melanocortin tone at the postsynaptic level and via direct inhibition of POMC (43). The opposite does not occur, favoring dietary intake and decreased energy expenditure in the absence of reciprocal inhibition of the POMC system on the NPY/AgRP.

Two neuropeptides are expressed by neurons in the lateral hypothalamus: melanin-concentrating hormone $(\mathrm{MCH})$ and orexins $(42)$. MCH stimulates appetite, possibly induced by the flavor of foods (47). The MCH producers neurons in the lateral hypothalamus are projected to the centers of smell and other areas of cerebral cortex, being inhibited by MSH producers neurons and neurons stimulated by NPY/AgRP (47). Orexins have secondary effects on food intake (42). The exact sites targeted by $\mathrm{MCH}$ neurons and orexins for induction of feeding behavior remains being determined.

\section{Brain stem}

The brain stem is classically understood as the center for detection and response to hunger/satiety signals (47). The dorsal vagal complex is comprised of the nucleus of the solitary tract (NST), the dorsal motor nucleus of the vagus (vagal motor neurons) and the area postrema. Sensory afferent signals carried by glossopharyngeal and vagus nerves include indications of taste, gastric stretch, and levels of glucose and lipids in the liver and portal vein. This information is relayed to the dorsal motor nucleus of the vagus, located ventrally to the NTS, which is the primary site of motor effectors into the intestine (47). 
Table 1. Summary of key peptides and neurotransmitters involved in the regulation of body weight

\begin{tabular}{|c|c|c|c|c|c|c|}
\hline & Production site & $\begin{array}{l}\text { Stimulation of } \\
\text { production }\end{array}$ & $\begin{array}{l}\text { Production } \\
\text { inhibitors }\end{array}$ & Action & $\begin{array}{l}\text { Effects on the } \\
\text { regulation of } \\
\text { hunger }\end{array}$ & Effects on EE \\
\hline \multicolumn{7}{|l|}{ Afferent system } \\
\hline Leptin & Adipose tissue & $\begin{array}{l}\text { Postprandial period } \\
\text { Insulin }\end{array}$ & Fast & $\begin{array}{c}\text { Inhibition of NPY/ } \\
\text { AgRP } \\
\text { Increased release of } \\
\alpha-M S H, C R H \text { and } \\
\text { CART }\end{array}$ & Anorexigenic action & Increases \\
\hline Ghrelin & Stomach, primarily & $\begin{array}{c}\text { Fast } \\
\text { Preprandial period }\end{array}$ & Postprandial period & $\begin{array}{l}\text { Activation of NPY/ } \\
\text { AgRP }\end{array}$ & Orexigenic action & Decreases \\
\hline GLP-1 & Small intestine & Postprandial period & Fast & $\begin{array}{l}\text { Increases secretion } \\
\text { of insulin-dependent } \\
\text { glucose } \\
\text { Increases fatty acid } \\
\text { synthesis }\end{array}$ & Anorexigenic action & No effect \\
\hline Insulin & Pancreas & Postprandial period & $\begin{array}{c}\text { Overnight fast } \\
\text { Preprandial period }\end{array}$ & $\begin{array}{l}\text { Production of } \\
\text { catabolic } \\
\text { neuropeptides }\end{array}$ & $\begin{array}{l}\text { Anorexigenic action } \\
\text { in the CNS }\end{array}$ & No effect \\
\hline \multicolumn{7}{|c|}{ Central nervous system } \\
\hline NPY & $\begin{array}{c}\text { Arcuate nucleus of } \\
\text { MH }\end{array}$ & $\begin{array}{c}\text { Fast } \\
\text { Ghrelin }\end{array}$ & $\begin{array}{l}\text { Leptin } \\
\text { Glucose }\end{array}$ & $\begin{array}{l}\text { Increases food } \\
\text { intake } \\
\text { Increases } \\
\text { lipogenesis in } \\
\text { animals }\end{array}$ & Orexigenic action & Decreases \\
\hline $\mathrm{AgRP}$ & $\begin{array}{c}\text { Arcuate nucleus of } \\
\text { MH }\end{array}$ & $\begin{array}{l}\text { Fast } \\
\text { Ghrelin }\end{array}$ & Leptin & $\begin{array}{l}\text { Antagonizes the } \\
\text { effects of MC4R }\end{array}$ & Orexigenic action & Decreases \\
\hline $\mathrm{MCH}$ & LH & Flavor of foods & $\begin{array}{l}\text { MSH-producing } \\
\text { neurons }\end{array}$ & $\begin{array}{l}\text { Uncertain } \\
\text { Probable link with } \\
\text { the NAc }\end{array}$ & Orexigenic action & No effect \\
\hline$\alpha-M S H$ & $\begin{array}{c}\text { Arcuate nucleus of } \\
\text { MH }\end{array}$ & Leptin & AgRP & $\begin{array}{l}\text { Agonist for the } \\
\text { MC4R }\end{array}$ & Anorexigenic action & Increases \\
\hline \multicolumn{7}{|l|}{ Efferent system } \\
\hline Irisin & Myocytes & Exercise & Unknown & $\begin{array}{l}\text { Induces "browning" } \\
\text { of the SAT by } \\
\text { increasing the } \\
\text { expression of UCP1 }\end{array}$ & $\begin{array}{c}\text { No direct effect on } \\
\text { hunger }\end{array}$ & Increases \\
\hline $\begin{array}{l}\text { Serotonin/ } \\
\text { Norepinephrine }\end{array}$ & $\begin{array}{c}\text { Autonomous nervous } \\
\text { system }\end{array}$ & $\begin{array}{l}\text { Environmental } \\
\text { factors: low } \\
\text { temperatures, diet }\end{array}$ & Weight loss & $\begin{array}{c}\text { Increases } \\
\text { sympathetic activity } \\
\text { Thermogenesis } \\
\text { Lipolysis in adipose } \\
\text { tissue }\end{array}$ & Anorexigenic action & Increases \\
\hline Thyroid hormones & Thyroid & $\begin{array}{l}\text { Exposure to cold } \\
\text { Fever } \\
\text { High calorie diet }\end{array}$ & $\begin{array}{c}\text { Critical illness } \\
\text { Caloric restriction } \\
\text { Drugs }\end{array}$ & $\begin{array}{l}\text { Regulates obligatory } \\
\text { and adaptive } \\
\text { thermogenesis }\end{array}$ & $\begin{array}{l}\text { Modulates appetite } \\
\text { according to the } \\
\text { state of hyper or } \\
\text { hypothyroidism }\end{array}$ & Increases \\
\hline
\end{tabular}

AgRP: Agouti-related peptide protein; $\alpha$-MSH: alpha-melanocyte-stimulating hormone; CART: cocaine and amphetamine regulated transcript; CNS: Central Nervous System; CRH: corticotropin releasing hormone; EE: energy expenditure; GLP1: glucagon like-peptide 1; LH: lateral hypothalamus; MC4R: melanocortin 4 receptor; MCH: melanin-concentrating hormone; MH: medial hypothalamus; NAc: Nucleus accumbens; NPY: neuropeptide Y; SAT: subcutaneous adipose tissue; UCP1: uncoupling protein 1. 


\section{EFFERENT SYSTEM: REGULATION OF ENERGY EXPENDITURE, EFFERENT AUTONOMIC AND ENDOCRINE SYSTEMS}

\section{Energy expenditure}

Ultimately, obesity results from an imbalance between energy input and energy output. Energy expenditure comprises combustion of substrates by oxygen and body's work and is divided into four types: (1) obligatory thermogenesis, related to cellular metabolism, functioning of organs, maintenance of the body's vital functions; (2) postprandial thermogenesis, or the thermal effect of food; (3) thermogenesis resulting from physical activity; and (4) adaptive thermogenesis (48). It has been postulated that a deficit in energy expenditure could contribute to the storage of triglycerides leading to obesity.

The obligatory thermogenesis is also referred to as resting energy expenditure or resting metabolic rate (RMR), representing approximately $70 \%$ of energy expenditure (42). Most studies do not support the involvement of a defect in RMR in the development of obesity. Obese individuals usually have greater RMR than lean persons because greater lean and adipose tissue cell mass excess (49). Ravussin and cols. concluded that the most important factor determining both the increased RMR and energy expenditure during $24 \mathrm{~h}$ in obese when compared to control subjects is the increased free fat mass (49). Some studies, however, have shown that a low energy expenditure could play a role in energy imbalance and obesity. A longitudinal study showed that a low rate of energy expenditure adjusted for body composition could be a predictor of weight gain in population prone to obesity (50). Another prospective study evaluated the energy metabolism and weight changes in Pima Indians, one of the most obese populations in the world (51). In this study, both total caloric intake and RMR were significantly associated with changes in weight in an average period of four years. Weight loss is associated with a reduction in energy expenditure that is out of proportion to changes in lean body mass, and it appears to persist indefinitely as long as the reduced weight is maintained (52).

The oxygen consumption increased (approximately $50 \mathrm{kcal}$ to $100 \mathrm{kcal}$ over a period of 4 hours to 8 hours) after the ingestion of food is named thermic effect of food (53). There are many factors that can influence it, as meal size, composition meal, physical activity and stands out the insulin resistance. In animal models, the association between obesity and decreased sympathetic nervous system (SNS) activity has consistently been found (53). The normal response (increased oxygen consumption) to a high fat diet is absent in mice without $\beta$-adrenergic receptor (53). In humans, it is likely that obese subjects have smaller but potentially important reduction in thermic effect of food from the insulin resistance and attenuated SNS activity (53).

The most variable part of energy expenditure is that corresponding to physical activity: exercise and non-exercise activity thermogenesis, which includes involuntary activities such as spontaneous muscle contractions, maintaining posture and involuntary movements, both representing 20\% of energy expenditure (47). Physical activity has short and long-term effects on energy expenditure. Acutely, it induces an increase in oxygen consumption (47). Irisin levels are increased in response to acute exercise as described in the section "Role of muscle tissue". In addition, it may have long-term effects on RMR, which may be promoted by stimulants of adaptive thermogenesis, as excess calories (42). It is unknown whether obese persons expend less total energy on daily physical activity than lean individuals do or if they are less active (54). Obese persons expend the same amount of energy as lean persons to perform the same amount of work during non-weight bearing activity (42). However, during weight-bearing activities, obese persons expend more energy than lean ones because more work is required to carry their greater body weight (55). It is estimated that in obese persons, the energy deficit created by exercise is usually much less and requires more effort than the energy deficit created by a reduced-calorie diet (47).

Adaptive thermogenesis corresponds to changes in energy expenditure as a function of thyroid hormones administration, exposure to cold and food intake, and accounts for $10 \%$ of energy expenditure (48). Thyroid hormones play a critical role in both obligatory and adaptive thermogenesis. In complete absence of thyroid hormone, RMR could be reduced by at least 30\% (56). In response to an environment with low temperature, the SNS encourages a thermogenic response of brown adipose tissue with rapid increase in T3 levels. Although thyroid hormones are critical for the regulation of RMR and adaptive thermogenesis, their effects on weight in the absence of diseases such as hyper or hypothyroidism are difficult to determine. The effects of administration of daily 
injections of T3 or GC-1 (a synthetic analogue, selective for the $\beta$ type thyroid receptor) at equimolar doses, for 6 weeks, on different metabolic parameters were assessed in rodents (57). In this study, animals treated with T3 or GC- 1 lost $70 \%$ and $20 \%$ of the fat mass, respectively, compared to controls, which gained $80 \%$ of fat mass, with no difference in the gain of fat-free mass. The development of synthetic analogues of thyroid hormones with selective effect on the $\mathrm{RMR}$, adaptive thermogenesis and metabolic profile, without side effects on other organs, is a promising area in the treatment of obesity (57).

The brown adipose tissue regulates energy expenditure through adaptive thermogenesis, a process that results in heat production by mitochondria to maintain normal body temperature. The activity of brown adipose tissue increases during childhood and adolescence, reaching a peak at 13 years of age, with a tendency to decrease progressively with increased age (58). The brown adipose tissue was not previously associated with thermogenesis in adults. However, observational studies using positron emission tomography and computerized tomography with 18F-fluorodeoxyglucose have shown the presence of metabolically active brown adipose tissue in healthy adults when exposed to cold (59). Thus, the activation of brown adipose tissue may be an important component of energy expenditure stimulated by cold in adults. Moreover, the activity of brown adipose tissue is inversely related to BMI, age and percentage of body fat (58).

\section{Irisin}

Irisin is secreted by myocytes and appears to mediate the beneficial effects of exercise on metabolism. Irisin, secreted into the blood as a product of fibronecting type III domain containing 5 (FNDC5), is induced by exercise and stimulates the transformation of white adipose tissue into brown adipose tissue, an effect known as "browning" of subcutaneous adipose tissue, by increasing the expression of uncoupling protein 1 (UCPl, thermogenin) (60). This effect leads to increased energy expenditure, potentially reflected in the reduction of body weight and the incidence of type 2 DM. Böstrom and cols. examined the effect of exercise on FNDC5 expression in the skeletal muscle of mice after 3 weeks of resistance exercise (60). There was a significant increase in both FNDC5 and plasma levels of irisin, resulting in improved glucose tolerance and reduced weight of mice submitted to exercise (60). Similar to what occurs in mice, the gene is expressed in the muscle of humans (61). Although irisin is identical in humans and rodents, the reproducibility of the effects of different stimuli in rodents is still doubtful in humans. Since that formation of brown adipose tissue has shown antidiabetes and antiobesity effects in both murine and human models, administration of analogues of irisin is a potentially attractive therapeutic target for metabolic disorders, especially in patients unable to perform physical activity (62).

\section{Efferent autonomic}

Regarding the contribution of the SNS, several neuropeptides, monoamines and drugs involved in the modulation of food intake and energy storage have reciprocal effects on sympathetic activity and adaptive thermogenesis (63). Both serotonin and norepinephrine reduce food intake and increase sympathetic activity (63). Mice expressing no adrenergic receptors develop severe obesity due to impaired diet-induced thermogenesis (63). Decreased SNS activity has been described in humans with obesity (63). Reduced sympathetic activity plays an opposite role in the adipose tissue: in white adipose tissue, there is a recruitment of new adipocytes that will result in hypertrophy and overdevelopment this cell; in the brown adipose tissue, an decrease in SNS activity will result in an overall decreased thermogenesis by two ways: decreasing the amount and activity of UCPI and, decreasing the number of brown adipocytes (6).

\section{GUT MICROBIOTA}

Dietary habits are considered one of the main factors that contribute to the diversity of human gut microbiota (64). Microbial changes in the human gut have been proposed as another possible cause of obesity (65). Many studies have reported shifts in the relative abundance of bacterial communities in the gut microbiota of obese relative to normal-weight individuals, and each study has attempted to link obesity with a species- or genus-specific composition profile of the gut microbiota (64). Meta-analyses revealed no difference in the Bacteroidetes concentrations between obese and normal weight humans (66). Other meta-analyses revealed that obese subjects present less Firmicutes, Bifidobacteria and Methanobrevibacter spp. than nonobese subjects do in their gut flora (8). However, it is still 
poorly understood how the dynamics and composition of intestinal microbiota are affected by diet or other lifestyle factors. It is believed that gut microbiota could affect body weight in experimental animals (and probably in humans) by several mechanisms, including effects on energy metabolism, low-grade inflammation, and altered gut permeability (67). Further studies should be conducted to clarify how gut microbial communities normally operate, and how they may be altered by probiotic, prebiotic, and antibiotic interventions to promote weight loss (64).

\section{SHORT AND LONG-TERM PERSISTENCE OF HORMONAL ADAPTATIONS TO WEIGHT LOSS}

After a period of weight loss induced by dieting, the body lay hold on to a series of adjustments in order to restrict the weight loss and prevent starvation. Calorie restriction induces compensatory short and long term mechanisms that will promote regain weight in most patients in treatment. The extremely high failure rate (> 80\%) to keep the reduced weight after successful weight loss is due to adaptation processes of the body to maintain body energy stores (68). Increased hunger and decreased satiety are secondary to increased ghrelin following weight loss (69). Moreover, significant and persistent reductions in energy expenditure as well as reductions in anorexigenic hormones as leptin appear to persist for at least one year following weight reduction and may remain altered indefinitely in a manner that promotes increased energy intake and ultimately weight regain (69). As previously documented, obese individuals undergoing weight loss through diet exhibit an approximate $28 \%$ decrease in energy expenditure (70).

\section{CONCLUSION}

The determination of body weight results, ultimately, from a complex interaction of peripheral signals involving the gastrointestinal tract, adipose tissue and muscle with the CNS. The increasingly detailed mapping of effector pathways that regulate body weight in response to afferent information from peripheral adiposity signals has produced a series of targets for new anti-obesity drugs. Although several components that participate in energy homeostasis have been identified, there is a need to know further details about their actions as well as their interactions with environmental and psychosocial factors in the development of human obesity. For most obese persons, negative energy balance is more readily achieved by decreasing food intake than by increasing physical activity. Therefore, dietary intervention is considered the cornerstone of weight-loss therapy. Weight-loss diets generally involve modifications of energy content and macronutrient composition. However, the degree of weight loss achieved primarily depends on the energy content, rather than the relative macronutrient composition of the diet. Since the adaptive biologic responses to weight loss are prone to promote energy accumulation, individuals must restrict energy intake and increase energy expenditure indefinitely to avoid weight regain.

Author's contributions: Milene Moehlecke and Cristiane Bauermann Leitão wrote the initial manuscript. Milene Moehlecke and Cristiane Bauermann Leitão conceived the idea. All authors contributed to finding references and correcting the manuscript. All authors read and approved the final manuscript.

Disclosure: no potential conflict of interest relevant to this article was reported.

\section{REFERENCES}

1. Flegal KM, Carroll MD, Kit BK, Ogden CL. Prevalence of obesity and trends in the distribution of body mass index among US adults, 1999-2010. JAMA. 2012;307(5):491-7.

2. Janssen I, Katzmarzyk PT, Ross R. Body mass index, waist circumference, and health risk: evidence in support of current National Institutes of Health guidelines. Arch Intern Med. 2002;162(18):2074-9.

3. Simpson JA, Maclnnis RJ, Peeters A, Hopper JL, Giles GG, English DR. A comparison of adiposity measures as predictors of all-cause mortality: the Melbourne Collaborative Cohort Study. Obesity (Silver Spring). 2007;15(4):994-1003.

4. Godoy-Matos AF, Guedes EP, Carraro L, Lopes AC, Mancini MC, Suplicy HL, et al. Diretrizes Brasileiras de Obesidade - Associação Brasileira para o Estudo da Obesidade e da Síndrome Metabólica. 2009-2010. p. 17-24.

5. Gao Q, Horvath TL. Neurobiology of feeding and energy expenditure. Annu Rev Neurosci. 2007;30:367-98.

6. Penicaud L, Cousin B, Leloup C, Lorsignol A, Casteilla L. The autonomic nervous system, adipose tissue plasticity, and energy balance. Nutrition. 2000;16(10):903-8.

7. Cnop M, Landchild MJ, Vidal J, Havel PJ, Knowles NG, Carr DR, et al. The concurrent accumulation of intra-abdominal and subcutaneous fat explains the association between insulin resistance and plasma leptin concentrations: distinct metabolic effects of two fat compartments. Diabetes. 2002;51(4):1005-15.

8. Rodrigues AM, Suplicy HL, Radominski RB. Neuroendocrine control of food intake: implications in the genesis of obesity. Arq Bras Endocrinol Metab. 2003;47(4):398-409.

9. Saper CB, Chou TC, Elmquist JK. The need to feed: homeostatic and hedonic control of eating. Neuron. 2002;36(2):199-211.

10. Cummings $D E$, Shannon $M H$. Roles for ghrelin in the regulation of appetite and body weight. Arch Surg. 2003;138(4):389-96.

11. Hukshorn CJ, Saris WH. Leptin and energy expenditure. Curr Opin Clin Nutr Metab Care. 2004;7(6):629-33. 
12. Fukuhara $A$, Matsuda M, Nishizawa M, Segawa K, Tanaka M, Kishimoto $\mathrm{K}$, et al. Visfatin: a protein secreted by visceral fat that mimics the effects of insulin. Science. 2005;307(5708):426-30.

13. Chang YH, Chang DM, Lin KC, Shin SJ, Lee YJ. Visfatin in overweight/obesity, type 2 diabetes mellitus, insulin resistance, metabolic syndrome and cardiovascular diseases: a meta-analysis and systemic review. Diabetes Metab Rev. 2011;27(6):515-27.

14. Stastny J, Bienertova-Vasku J, Vasku A. Visfatin and its role in obesity development. Diabetes Metab Syndr. 2012;6(2):120-4.

15. Galic S, Oakhill JS, Steinberg GR. Adipose tissue as an endocrine organ. Mol Cell Endocrinol. 2010;316(2):129-39.

16. Damiani D, Damiani D, Menezes Filho HC. Appetite control: metabolic and cognitive mechanisms. Pediatria (São Paulo). 2010;32(3):211-22.

17. Hotta K, Funahashi T, AritaY,Takahashi M, Matsuda M, OkamotoY, et al. Plasma concentrations of a novel, adipose-specific protein, adiponectin, in type 2 diabetic patients. ArteriosclerThromb Vasc Biol. 2000;20(6):1595-9.

18. Kissebah AH, Sonnenberg GE, Myklebust J, Goldstein M, Broman $\mathrm{K}$, James RG, et al. Quantitative trait loci on chromosomes 3 and 17 influence phenotypes of the metabolic syndrome. Proc Natl Acad Sci U S A. 2000;97(26):14478-83.

19. Park HK, Ahima RS. Resistin in rodents and humans. Diabetes Metab. 2013;37(6):404-14.

20. Rajkovic N, Zamaklar M, Lalic K, Jotic A, Lukic L, Milicic T, et al. Relationship between obesity, adipocytokines and inflammatory markers in type 2 diabetes: relevance for cardiovascular risk prevention. Int J Environ Res Public Health. 2014;11(4):4049-65.

21. Rachwalik M, Zysko D, Diakowska D, Kustrzycki W. Increased content of resistin in epicardial adipose tissue of patients with advanced coronary atherosclerosis and history of myocardial infarction. Thoracic Cardiovasc Surg. 2014;62(7):554-60.

22. Kronenberg HM, Polonsky KS, Larsen PR. Neuroendocrine Control of Energy Stores. Williams Textbook of Endocrinology. 2010(11 th):1218-53.

23. Cummings $D E$, Purnell JO, Frayo RS, Schmidova $K$, Wisse BE, Weigle DS. A preprandial rise in plasma ghrelin levels suggests a role in meal initiation in humans. Diabetes. 2001;50(8):1714-9.

24. Tschop M, Smiley DL, Heiman ML. Ghrelin induces adiposity in rodents. Nature. 2000:407(6806):908-13.

25. Wren AM, Seal LJ, Cohen MA, Brynes AE, Frost GS, Murphy KG, et al. Ghrelin enhances appetite and increases food intake in humans. J Clin Endocrinol Metab. 2001;86(12):5992.

26. Ezcurra M, Reimann F, Gribble FM, Emery E. Molecular mechanisms of incretin hormone secretion. Curr Opinion Pharmacol. 2013;13(6):922-7.

27. Astrup A, Carraro R, Finer N, Harper A, Kunesova M, Lean ME, et al. Safety, tolerability and sustained weight loss over 2 years with the once-daily human GLP-1 analog, liraglutide. Int J Obes (Lond). 2012;36(6):843-54.

28. Verdich C, Flint A, Gutzwiller JP, Naslund E, Beglinger C, Hellstrom PM, et al. A meta-analysis of the effect of glucagon-like peptide-1 (7-36) amide on ad libitum energy intake in humans. J Clin Endocrinol Metab. 2001;86(9):4382-9.

29. Dickson SL, Shirazi RH, Hansson $C$, Bergquist $F$, Nissbrandt $H$, Skibicka KP. The glucagon-like peptide 1 (GLP-1) analogue, exendin-4, decreases the rewarding value of food: a new role for mesolimbic GLP-1 receptors. J Neurosci. 2012;32(14):4812-20.

30. Sheikh A. Direct cardiovascular effects of glucagon like peptide-1. Diabetes Metab Syndr. 2013;5(1):47.

31. Yang H. Central and peripheral regulation of gastric acid secretion by peptide YY. Peptides. 2002;23(2):349-58.

32. Chelikani PK, Haver AC, Reidelberger RD. Intravenous infusion of peptide YY(3-36) potently inhibits food intake in rats. Endocrinology. 2005;146(2):879-88.
33. Harrold JA, DoveyTM, Blundell JE, Halford JC. CNS regulation of appetite. Neuropharmacology. 2012;63(1):3-17.

34. Overduin J, Gibbs J, Cummings DE, Reeve JR Jr. CCK-58 elicits both satiety and satiation in rats while CCK-8 elicits only satiation. Peptides. 2014;54:71-80.

35. Duca FA, Zhong L, Covasa M. Reduced CCK signaling in obeseprone rats fed a high fat diet. Horm Behav. 2013;64(5):812-7.

36. Lateef DM, Washington MC, Sayegh Al. The short term satiety peptide cholecystokinin reduces meal size and prolongs intermeal interval. Peptides. 2011;32(6):1289-95.

37. Pi-Sunyer X, Kissileff HR, Thornton J, Smith GP. C-terminal octapeptide of cholecystokinin decreases food intake in obese men. Physiol Behav. 1982;29(4):627-30.

38. Geary N. Endocrine controls of eating: CCK, leptin, and ghrelin. Physiol Behav. 2004;81(5):719-33.

39. Obici S, Feng Z, Karkanias G, Baskin DG, Rossetti L. Decreasing hypothalamic insulin receptors causes hyperphagia and insulin resistance in rats. Nat Neurosci. 2002;5(6):566-72.

40. Heymsfield SB, Greenberg AS, Fujioka K, Dixon RM, Kushner R, Hunt T, et al. Recombinant leptin for weight loss in obese and lean adults: a randomized, controlled, dose-escalation trial. JAMA. 1999;282(16):1568-75.

41. Shin AC, Zheng H, Berthoud HR. An expanded view of energy homeostasis: neural integration of metabolic, cognitive, and emotional drives to eat. Physiol Behav. 2009;97(5):572-80.

42. Jameson JL dGL. Appetite regulation and thermogenesis. Eur $\mathrm{J}$ Clin Nutr. 2010;1(6):542-54

43. Velloso LA.The brain is the conductor: diet-induced inflammation overlapping physiological control of body mass and metabolism. Arq Bras Endocrinol Metab. 2009;53(2):151-8.

44. Inytska O, Argyropoulos G. The role of the Agouti-Related Protein in energy balance regulation. Cell Mol Life Sci. 2008;65(17):2721-31.

45. Siljee JE, Unmehopa UA, Kalsbeek A, Swaab DF, Fliers E, Alkemade $A$. Melanocortin 4 receptor distribution in the human hypothalamus. Eur J Endocrinol. 2013;168(3):361-9.

46. Vaisse C, Clement K, Durand E, Hercberg S, Guy-Grand B, Froguel P. Melanocortin-4 receptor mutations are a frequent and heterogeneous cause of morbid obesity. J Clin Invest. 2000;106(2):253-62.

47. Kronenberg HM PK, Larsen PR. Neuroendocrine control of energy stores. Williams Textbook of Endocrinology. 2010.11 th:1218-53.

48. Ricquier D. Fundamental mechanisms of thermogenesis. $C R$ Biol. 2006;329(8):578-86

49. Ravussin E, Burnand B, Schutz $Y$, Jequier E. Twenty-four-hour energy expenditure and resting metabolic rate in obese, moderately obese, and control subjects. Am J Clin Nutr. 1982;35(3):566-73.

50. Ravussin E, Lillioja S, Knowler WC, Christin L, Freymond D, AbbottWG, et al. Reduced rate of energy expenditure as a risk factor for body-weight gain. N Engl J Med. 1988;318(8):467-72.

51. Tataranni PA, Harper IT, Snitker S, Del Parigi A, Vozarova B, Bunt $\mathrm{J}$, et al. Body weight gain in free-living Pima Indians: effect of energy intake vs expenditure. Int J Obes Relat Metab Disord. 2003;27(12):1578-83.

52. Matarese LE, Pories WJ. Adult weight loss diets: metabolic effects and outcomes. Nutr Clin Pract. 2014;29(6):759-67.

53. de Jonge L, Bray GA. The thermic effect of food and obesity: a critical review. Obes Res. 1997;5(6):622-31.

54. DeLany JP, Kelley DE, Hames KC, Jakicic JM, Goodpaster BH. High energy expenditure masks low physical activity in obesity. Int J Obes (Lond). 2013;37(7):1006-11.

55. Segal KR, Presta E, Gutin B. Thermic effect of food during graded exercise in normal weight and obese men. Am J Clin Nutr. 1984;40(5):995-1000.

56. Silva JE. The thermogenic effect of thyroid hormone and its clinical implications. Ann Intern Med. 2003;139(3):205-13. 
57. Villicev CM, Freitas FR, Aoki MS, Taffarel C, Scanlan TS, Moriscot AS, et al. Thyroid hormone receptor beta-specific agonist GC-1 increases energy expenditure and prevents fat-mass accumulation in rats. J Endocrinol. 2007;193(1):21-9.

58. Virtanen KA, Lidell ME, Orava J, Heglind M, Westergren R, Niemi $\mathrm{T}$, et al. Functional brown adipose tissue in healthy adults. $\mathrm{N}$ Engl J Med. 2009;360(15):1518-25.

59. Cypess AM, Lehman S, Williams G, Tal I, Rodman D, Goldfine AB, et al. Identification and importance of brown adipose tissue in adult humans. N Engl J Med. 2009;360(15):1509-17.

60. Boström P, Wu J, Jedrychowski MP, Korde A, Ye L, Lo JC, et al. A PGC1-alpha-dependent myokine that drives brown-fatlike development of white fat and thermogenesis. Nature. 2012;481(7382):463-8.

61. Huh JY, Panagiotou G, Mougios V, Brinkoetter M, Vamvini MT, Schneider BE, et al. FNDC5 and irisin in humans: I. Predictors of circulating concentrations in serum and plasma and II. mRNA expression and circulating concentrations in response to weight loss and exercise. Metabolism. 2012;61(12):1725-38.

62. Pedersen BK. A muscular twist on the fate of fat. N Engl J Med. 2012;366(16):1544-5.
63. Bray GA. Reciprocal relation of food intake and sympathetic activity: experimental observations and clinical implications. Int $\mathrm{J}$ Obes Relat Metab Disord. 2000.24 Suppl 2:S8-17.

64. Angelakis E, Armougom F, Million M, Raoult D. The relationship between gut microbiota and weight gain in humans. Future Microbiol. 2012;7(1):91-109.

65. Ley RE, Turnbaugh PJ, Klein S, Gordon JI. Microbial ecology: human gut microbes associated with obesity. Nature. 2006;444(7122):1022-3.

66. Turnbaugh PJ, Hamady M, Yatsunenko T, Cantarel BL, Duncan A, Ley $\mathrm{RE}$, et al. A core gut microbiome in obese and lean twins. Nature. 2009;457(7228):480-4.

67. Tremaroli V, Backhed F. Functional interactions between the gut microbiota and host metabolism. Nature. 2012;489(7415):242-9.

68. Weck M, Bornstein SR, Barthel A, Bluher M. Strategies for successful weight reduction - focus on energy balance. Dtsch Med Wochenschr. 2012;137(43):2223-8.

69. Sumithran P, Prendergast LA, Delbridge E, Purcell K, Shulkes A, Kriketos $A$, et al. Long-term persistence of hormonal adaptations to weight loss. N Engl J Med. 2011;365(17):1597-604.

70. Leibel RL, Hirsch J. Diminished energy requirements in reducedobese patients. Metabolism. 1984;33(2):164-70. 